\title{
INFUSÃO DE ERVA-MATE TEM EFEITOS NA PREVENÇÃO DA DOENÇA DE PARKINSON EM MODELO IN VITRO
}

Danieli Monteiro Pillar; Universidade Federal de Santa Maria; danielipillar@gmail.com;

Bruna Chitolina; Universidade Federal de Santa Maria; brunachitolina@hotmail.com;

Ivana Beatrice Mânica da Cruz; Universidade Federal de Santa Maria; ibmcruz@hotmail.com;

Marta Maria Medeiros Frescura Duarte; Universidade Luterana do Brasil; duartmm@hotmail.com ;

Tábada Samantha Marques Rosa; Universidade Federal de Santa Maria; sa_marqs@hotmail.com;

Verônica Farina Azzolin; Universidade Federal de Santa Maria; azzolinveronica@hotmail.com;

Aron Ferreira da Silveira; Universidade Federal de Santa Maria; aronfer@gmail.com;

Euler Esteves Ribeiro; Fundação Universidade Aberta do Estado do Amazonas- Manaus-AM; unatieuler@gmail.com;

Ednea Aguiar Maia-Ribeiro; Fundação Universidade Aberta do Estado do Amazonas- Manaus-AM; edneamaiaribeiro@gmail.com;

Raquel Souza-Praia; Fundação Universidade Aberta do Estado do Amazonas- Manaus-AM; rak8113@icloud.com;

Fernanda Barbisan; Universidade Federal de Santa Maria; fernandabarbisan@gmail.com

\section{RESUMO}

Introdução: Doença de Parkinson (DP) é resultado da associação entre fatores genéticos e ambientais e da combinação desses fatores com o envelhecimento, ocasionando disfunções mitocôndrias e de membrana celular culminando com o estresse oxidativo e inflamação crônica. Compostos bioativos com capacidade antioxidante e anti-inflamatória podem reduzir o estresse oxidativo. A erva-mate (Ilex paraguariensis), altamente consumida principalmente sob a forma de chás e chimarrão, é rica em compostos fotoquímicos com capacidade antioxidante. Objetivo: Investigar o papel da erva-mate em modelo in vitro de Doença de Parkinson. Métodos: A linhagem celular SHSY-5Y foi cultivada em condições padronizadas. Inicialmente as células foram expostas a uma infusão de erva-mate $(10 \mathrm{mg} / \mathrm{mL})$ por 24 horas, adicionou-se a rotenona (indutor de DP in vitro), as células permaneceram em cultivo por 72 horas. Então, foram realizadas análises relacionadas ao metabolismo oxidativo e inflamatório. Resultados: Células expostas somente a rotenona apresentaram forte elevação nos marcadores oxidativos e citocinas inflamatórias, além de queda nos níveis da IL-10 (anti-inflamatória) em relação ao grupo controle. Quando houve tratamento com erva-mate antes da exposição a rotenona houve uma diminuição significativa nos marcadores oxidativos, com destaque para 8-OHdG (dano ao DNA). Os marcadores inflamatórios aqui analisados tiveram significativa queda e concomitantemente a erva-mate foi capaz de elevar os níveis da IL-10. Conclusão: Demonstrou-se efeito preventivo da infusão de erva-mate à DP, mais estudos em modelos animais, precisam ser realizados para comprovação dessa hipótese e possível utilização da erva-mate para o desenvolvimento de medicamentos.

Palavras-Chave: Chimarrão; Ilex paraguariensis; Envelhecimento. 